\title{
MAJORIZATION AND REFINEMENTS OF HERMITE-HADAMARD INEQUALITY
}

\author{
MAREK NIEZGODA
}

Abstract. In this note we use majorization methods to derive and analyze refinements of HermiteHadamard inequality for a convex function.

Mathematics subject classification (2010): 26A42, 26A51, 26D15.

Keywords and phrases: Convex function, Hermite-Hadamard inequality, majorization, column stochastic matrix, Sherman inequality.

\section{REFERENCES}

[1] J. BorCEA, Equilibrium points of logarithmic potentials, Trans. Amer. Math. Soc., 359 (2007) 32093237.

[2] W. W. Breckner And T. TRIF, Convex Functions and Related Functional Equations: Selected Topics, Cluj University Press, Cluj, 2008.

[3] A.-M. Burtea, Two examples of weighted majorization, Annals of the University of Craiova, Mathematics and Computer Science Series, 37 (2000) 92-99.

[4] P. S. Bullen, Error estimates for some elementary quadrature rules, Univ. Beograd. Publ. Elektrotehn. Fak. Ser. Mat. Fiz., 602-633 (1978) 97-103.

[5] S. S. DRAGOMIR, $n$-points inequalities of Hermite-Hadamard type for $h$-convex functions on linear spaces, Armenian Journal of Mathematics, 8 (2016) 38-57.

[6] A. El FARISSI, Simple proof and refinement of Hermite-Hadamard inequality, J. Math. Inequal., 4 (2010) 365-369.

[7] P. C. HAMmER, The midpoint method of numerical integration, Math. Mag., 31 (1957/1958) 193-195.

[8] M. Klaričić-BAKula, J. PeČAriĆ And J. Perić, Extensions of the Hermite-Hadamard inequality with applications, Math. Inequal. Appl., 12 (2012) 899-921.

[9] Z. LATREUCH AND B. BelaïDI, New inequalities for convex sequences with applications, Int. J. Open Problems Comput. Math., 5 (2012) 15-27.

[10] A. W. Marshall, I. Olkin And B. C. ARnold, Inequalities: Theory of Majorization and Its Applications, Second Edition, Springer, New York, 2011.

[11] C. P. Niculescu And L.-E. Persson, Old and new on the Hermite-Hadamard inequality, Real Analysis Exchange, 29 (2003/2004) 663-685.

[12] M. NiezGodA, Sherman, Hermite-Hadamard and Fejér like inequalities for convex sequences and nondecreasing convex functions, Filomat, 31 (2017) 2321-2335.

[13] S. Sherman, On a theorem of Hardy, Littlewood, Pólya, and Blackwell, Proc. Nat. Acad. Sci. USA, 37 (1957) 826-831. 